\title{
Breast Implant Illness: Mini
}

\section{Review}

\section{Samantha Muktar and Dibyesh Banerjee*}

St George's University Hospital, Blackshaw Road, Tooting, London SW17 0QT, United Kingdom

Received: 25 August, 2020

Accepted: 14 September, 2020

Published: 15 September, 2020

*Corresponding author: Dibyesh Banerjee, MD, MS, FRCSEd, FRCS, Breast Unit, Rose Centre, St George's University Hospital, Blackshaw Road, Tooting, London SW17 0QT, United Kingdom, E-mail: Dibyesh@aol.com

https://www.peertechz.com

Check for updates
Breast Implant Illness (BII) is a collective term used by woman who have breast implants either from breast reconstruction or augmentation and summarises a group of systemic symptoms. These systemic symptoms can include fatigue, chest pain, hair loss, headaches, chills, photosensitivity, chronic pain, rash, body odor, anxiety, brain fog, sleep disturbance, depression, neurologic issues and hormonal issues. It is also sometimes referred to as 'autoimmune/inflammatory syndrome induced by adjuvants'. BII is not currently recognised as an official medical diagnosis, it is poorly understood and hasn't been studied much as a unique condition. The most widely accepted hypothesis is that the silicone within the implants may act as an autoimmune adjuvant.

To fully understand BII it is worth briefly reviewing the history of it as an entity. In the 1980s, following the report of cases of human adjuvant disease related to silicone gel implants there was an abundance of case reports and small series undertaken followed by a rush of media attention [1,2]. Subsequently in the 1990sm, as concerns mounted, the Food and Drug Administration (FDA) issued a moratorium that severely limited use of silicone breast implants. In 1999, The Institute of Medicine Committee on the 'Safety of Silicone' conducted an extensive review of the available literature and concluded there was no demonstrated link between silicone implants and any systemic illness. There have been studies of many different sizes and design to look at the safety of breast implants themselves. These have looked at specific autoimmune disorders and diseases. Collectively, these studies show little to no links between breast implants and any disease [3]. In 2003, the U.S. FDA convened an advisory panel to consider specific aspects regarding breast augmentation and breast implant devices and in 2006 silicone breast implants were re-introduced into the market [4].

More recently, a study published in Australia has investigated other potential causes to explain the manifestation of systemic symptoms [5]. They prospectively followed 50 patients self- presenting with BII and analysed pre-operative symptoms, reported outcomes and assessed the type, histopathology and microbiology culture of the implants and capsules following explantation. The alternative aetiology for BII concluded by this study included; sub-clinical infection (biofilm), direct chemical toxicity, and HLA subtype incompatibility. The study identified positive bacterial cultures in $36 \%$ of the BII cohort and the most common organism isolated was P. Acnes. A slimy biofilm structure was clinically apparent during surgery in nearly all patients supporting the theory of chronic subclinical infection.

BII has become topical largely through media attention and via online social media platforms. On online forums, there are a number of global members of 'Breast Implant Illness Support Forums' and one Facebook group alone has more than 50,000 members who report symptoms of BII. It is reasonable to conclude that the rise of patient advocacy and communication through social media has led to an increasing number of presentations to surgeons [6].

BII is currently not recognised as a medical diagnosis and therefore there are no diagnostic criteria nor investigative protocols to treat it as such. Although there is no strong medical evidence for BII, various studies have shown different degrees of improvement in symptoms after removal of implants, some of which are temporary, and some showing permanent resolution of symptoms. On the whole, around $50 \%$ of women feel that their symptoms improve after implant removal. In this context, for a patient presenting with symptoms that selfidentify as BII, it would be advisable for surgeons to validate individual concerns. It is necessary to inform patients that currently there is no known mechanism by which implants can cause systemic symptoms, however, the surgeon should consider (following medical tests) offering patients removal of their breast implants if that is requested of them.

Often patients may also request a complete capsulectomy and to have this done 'en-bloc'. The concern is that leaving 
part of the capsule behind, even if it isn't thickened, could leave behind substances that can continue to cause the symptoms of breast implant illness and by removing it separately, this could cause some type of contamination of the area. The 'enbloc' concept is one of the medical inaccuracies perpetuated on the internet and on social media. There is no evidence that 'en-bloc' removal offers any benefit to the patient, and indeed this technique is more invasive and requires larger incisions. Further study is required to determine the best way to potentially screen patients prior to breast implant surgery and to determine which of the multitude of reported symptoms might improve with implant and capsule removal.

The British Association of Aesthetic Plastic Surgeons (BAAPS) [7], reports no current definitive evidence to support a direct link between breast implants and any specific disease process, however, validates the need for further research. They suggest surgeons should make patients aware of BII. Patients need the most up-to-date information possible, with the caveat that breast implant illness is poorly understood so it's difficult to give absolute information. On a personal note, we have not seen even a single patient with BII in our breast reconstructive practice over 15 years at this Institution. This includes over 650 post mastectomy reconstructions using silicone breast implants. It may be argued: are patients with breast cancer, undergoing implant based reconstructions somehow "immune" to developing BII symptoms? Clearly, more work needs to be done on this complex subject.

In summary, Breast Implant Illness is a phenomenon being discussed increasingly on the internet. At present, there is no evidence of a relationship between silicone breast implants and a specific disease process and more research is underway. We cannot yet define BII and therefore cannot say with certainty that it exists and at present there is no diagnostic process in place for patients that self-present with symptoms. That said, the lack of proven scientific evidence does not mean that the symptoms experienced by patients are not real and therefore these concerns still deserve our attention. As clinicians, we need to listen and acknowledge that patients may be experiencing symptoms. We must also ensure a general medical work-up is undertaken to investigate other causes and this can be with or without the involvement of a Rheumatologist. Any woman concerned about symptoms of BII should feel comfortable bringing this up with their surgeon. Listening to your patient and having open conversations will help to determine what is the best course of action to address the complaints and this can include implant removal in certain cases.

\section{References}

1. Baldwin CM, Kaplan EN (1983) Silicone-induced human adjuvant disease? Ann Plast Surg 10: 270-273. Link: https://bit.ly/32tWfKS

2. Sergott TJ, Limoli JP, Baldwin CM, Laub DR (1986) Human adjuvant disease possible autoimmune disease after silicone implan- tation: a review of the literature, case studies, and speculation for the future. Plast Reconstr Surg 78 104-114. Link: https://bit.ly/2FhBIAr

3. Institute of Medicine (US), Grigg M, Bondurant S, Ernster VL, Herdman R (2000) Information for Women About the Safety of Silicone Breast Implants. Washington (DC): National Academies Press (US); 2000. A Report of a Study by the Institute of Medicine. Link: https://bit.ly/3kbUCr2

4. Food and Drug Administration. Surgery Devices Panel of the Medical Devices Advisory Committee. 2003. Available at https://www.accessdata.fda.gov/ scripts/cdrh/cfdocs/cfAd- visory/details.cfm?mtg=388. Accessed November 8, 2018.

5. Lee M, Ponraja G, McLeod K, Chong S (2020) Breast Implant Illness: A Biofilm Hypothesis. Plastic and Reconstructive Surgery - Global Open 8: e2755. Link: https://bit.ly/3k8sBAC

6. Magnusson MR, Cooter RD, Rakhorst H, McGuire PA, Adams WP, et al. (2019) Breast Implant Illness: A Way Forward. Plast Reconstr Surg 143: 74S-81S Link: https://bit.ly/2ZAwEOn

7. Breast Implant IIIness - what we know, and what we don't know. Link: https://bit.ly/33ogfO1

\section{Discover a bigger Impact and Visibility of your article publication with}

Peertechz Publications

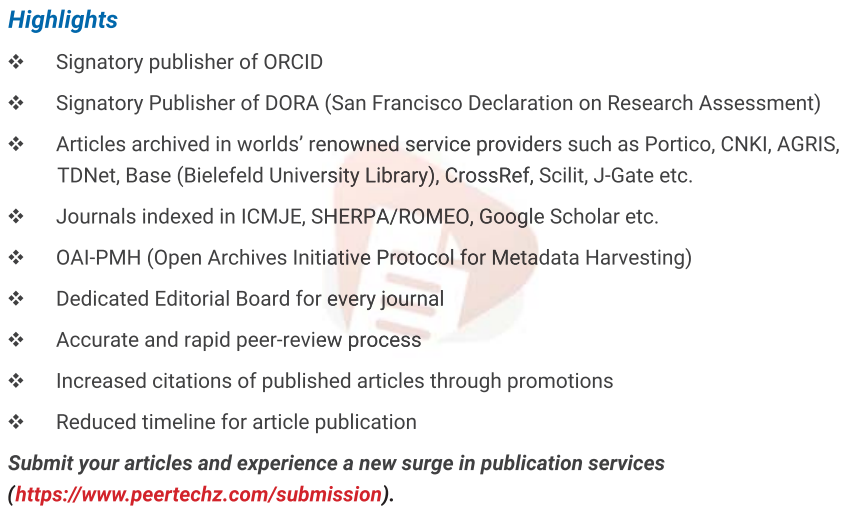

Peertechz journals wishes everlasting success in your every endeavours.

Copyright: @ 2020 Muktar S, et al. This is an open-access article distributed under the terms of the Creative Commons Attribution License, which permits unrestricted use, distribution, and reproduction in any medium, provided the original author and source are credited. 